\title{
ANAESTHESIA FOR DAY-CARE SURGERY: A SYMPOSIUM (II)*
}

\section{ORGANIZATION OF THE OUT-PATIENT SURGICAL FACILITY}

\author{
G. Edelist AND G. URBACH
}

\begin{abstract}
The organization of three main types of out-patient anaesthesia facility are discussed. These are the hospital unit with independent facilities, the integrated hospital unit and the independent out-patient surgical centre.

The use of an out-patient facility for minor surgical procedures has been suggested as a less expensive alternative to in-patient management. Some of the advantages and disadvantages are outlined.
\end{abstract}

THE RAPIDLY RISING cosTs of in-patient surgical care has led to an increased interest in the possibility of providing wider surgery and anaesthesia coverage on an out-patient basis. This should be of benefit to the patient, being less disruptive to his personal life and to the economy in general, cutting the costs of medical care. ${ }^{1}$

Out-patient facilities fall into three main categories

1. The elective out-patient surgical unit found within a hospital but with independent facilities.

2. The elective out-patient surgical unit found within a hospital but integrated with in-patient surgery.

3. The independent, free-standing, out-patient surgical centre.

The factors involved in the organization of any of the three types of out-patient facilities are common, although their advantages and disadvantages will differ. These factors are physical organization, type of surgery, choice of patient, recovery and discharge. Most of this paper will deal with the first type of facility since it is the one we are personally familiary with.

\section{HoSPITAL UNIT WITH INDEPENDENT FACILITIES}

An example of this type of facility is the unit we have at Mount Sinai Hospital in Toronto.

*Presented as a Panel at the Annual Meeting, Canadian Anaesthetists' Society, June 1979.

G. Edelist, M.D., F.R.C.P.(C), Professor; G. Urbach, M.D., F.R.C.P.(C), Assistant Professor. Department of Anaesthesia, University of Toronto Mount Sinai Hospital, 600 University Avenue, Toronto, Ontario, M5G IX5.

Canad. Anaesth. Soc. J., vol. 27, no. 4, July 1980

\section{Physical organization}

The patient reports to the clerk at the nursing station. Behind him is the waiting room for friends and relatives. A nurse will take him to the changing room where he will change into a hospital gown and then go to the preparation room to have his vital signs checked. He is also questioned regarding food intake, allergies, dentures, contact lenses etc. He will then wait in the patient-waiting area. Before the operation the surgeon will take him to the desk in the nursing station where informed consent will be obtained. Here also, the anaesthetist reviews the chart. The patient is then accompanied to one of the two operating rooms. One is used for general anaesthesia and one for locals. Both are similarly equipped because one cannot always be sure when a local might become a general anaesthetic, and general anaesthetics are frequently given in the local room. The operating rooms have the same equipment as those for in-patient surgery.

Postoperatively, the patients are taken to the recovery area, which is fully equipped with oxygen, suction and monitoring facilities. The recovery room area has seven beds. There is one registered nurse for each operating room and one nursing assistant between the two. The total staff of the facility includes five registered nurses, two nursing assistants, one clerk and one nursing supervisor to handle three thousand patients per year.

\section{Types of operations}

Only procedures that are relatively short (under one hour) are done in our unit. These procedures are chosen with an eye to the recovery period which should be no longer than three 
TABLE I

TYPES OF SURGERY

\begin{tabular}{ll}
\hline \hline $\begin{array}{l}\text { Eye } \\
\text { E.N.T. }\end{array}$ & $\begin{array}{l}\text { Excision of chalazion, strabismus correction, nasolacrimal probing } \\
\text { Myringotomy and insertion of tubes, laryngoscopy, bronchoscopy, } \\
\text { oesophagoscopy and dilatation }\end{array}$ \\
$\begin{array}{l}\text { Dentistry } \\
\text { Rectal }\end{array}$ & $\begin{array}{l}\text { Dental extraction, whole mouth restorations } \\
\text { Eynaecology }\end{array}$ \\
$\begin{array}{l}\text { EUA, D \& C diagnostic, therapeutic abortion, laparoscopy, tubal } \\
\text { coagulation }\end{array}$ \\
$\begin{array}{l}\text { Change of plaster, excision of exostosis, manipulations } \\
\text { General surgery }\end{array}$ \\
$\begin{array}{l}\text { Excision of ganglion, circumcision, breast biopsy, hernia repair in } \\
\text { children }\end{array}$ \\
Hrology \\
Hydrocoelectomy, testicular and prostatic biopsy, vasectomy, \\
cyctoscopy, retrograde pyelograpy, circumcision
\end{tabular}

hours in duration under normal circumstances (Table I).

\section{Choice of patient}

According to Schmidt the objective of outpatient anaesthesia is to provide safe anaesthetic and surgical care. ${ }^{2}$ This requires prior knowledge of the patient's physical status including laboratory findings as well as a competent anaesthetist. Patients admitted to the elective out-patient surgical unit are all A.S.A. Physical Status 1 or occasionally 2 . They have a history taken and physical examination done by their personal physician or in the General Practice Unit in our hospital. The record of this examination together with the results of the haemoglobin and urinalysis determination and any other laboratory work deemed appropriate by the physician are forwarded to the unit, where they are filed at the nursing station for presentation to the anaesthetist on the day of the operation. We also require that patients over 35 years of age have a chest $X$-ray and those over forty-five years of age have an electrocardiogram report available.

At the time when patients are seen by their surgeons and when the procedure is booked, they are given a detailed instruction form which includes the information that they must not eat or drink after midnight of the day before the operation and why this is necessary, and cautioning them that they must provide a responsible adult to accompany them home.

\section{Recovery and discharge}

A patient's stay in the recovery room will be longer compared with that of in-patients subject to similar anaesthesia, since out-patients need to recover more completely. ${ }^{2}$
After the patient is awake and oriented, he is allowed to sit, then stand and then walk. They are given milk and cookies, or coffee to ensure there is no nausea or vomiting. When they have reached this stage, the recovery-room nurse will notify the anaesthetist who will discharge the patient if a Rhomberg test is normal. The patients are cautioned not to drink alcohol until the following evening and not to drive for 24 hours. If they are still not considered "street fit" when the unit closes at 1730 , they are transferred to the emergency department where, if necessary, they may be kept in a "holding bed" overnight.

\section{INTEGRATED HOSPITAL UNIT}

A good example of a facility in category number two, that is within the hospital but integrated with in-patient surgery, is the Virginia Mason Hospital in Seattle, Washington. This facility is well described by Tompson, et $a l^{3}$ In brief the patient reports to a "short-stay desk" where the pertinent information is gathered about the patient's physical status and laboratory work-up. Also, consent forms are signed and the patient is told the particulars about his or her operation. He is given a brochure containing information about insurance coverage, billing procedure and out-patient surgery in general. The nurse-secretary at this desk has much greater responsibility than the clerk in our system. She discusses the next day operating schedule with a specially trained operating room nurse to integrate the out-patients into the in-patient operating schedule. She then phones the patient and informs him about the time and length of his operation. On the day of the procedure the patient is prepared in their emergency room and then has a 
pre-operative interview with the anaesthetist, who does a history and physical examination, after which an intravenous infusion is started. Under this system, much more work and time is required of the anaesthetist than in our facility where the history and physical examination are done before the patient's arrival at the hospital; but it is far better as far as interpersonal relationships and knowledge of the patient's status is concerned. It also optimizes the utilization of operating room and anaesthetic time.

\section{Independent OUt-Patient Surgical Centre}

This will have roughly the same physical organization, type of surgery, choice of patient and recovery and discharge procedures as the other types of facility. The best description of this type of unit is by Reed and Ford, founders of the Surgicenter in Phoenix, Arizona. ${ }^{4}$ They point out that this type of facility can cut costs because construction is cheaper. little laundry is required, there is no cafeteria and 24-hour X-ray and laboratory coverage are eliminated. Also, in order to provide excellent care, the physician should have privileges in an area hospital, adequate records should be kept, there must be good nursing coverage and there should be good $X$-ray and laboratory facilities. As well, the equipment to handle emergencies such as cardiac arrest and respiratory emergencies must be available.

The pioneer in the field of anaesthesia in a free-standing out-patient surgical service was Dr. Ralph M. Waters of cyclopropane fame. His anaesthesia clinic was started in 1919. Since then there has been a steady growth of this type of facility in the United States. Attempts to introduce it in Ontario have been blocked by the Provincial Government's refusal to extend O.H.J.P. coverage to a facility of this type.

The prime advantage of these facilities has been their economy, while their disadvantage has been the difficulty in effecting the transfer of patients to an in-patient facility when this becomes necessary for causes such as perforated uterus. delayed recovery from anaesthesia. bleeding. etc. which occur in from 1 to 4 per cent of cases.

This disadvantage does not occur in a hospital situation, but logistical foul-ups are much more likely to occur in a situation where there is a tie-in with in-patient surgery than with a self-contained unit.

In summing up, when a situation exists where the population increases and in-patient facilities remain static or as in the case of Ontario where there is an actual reduction of in-patient facilities through budget cuts and enforced bed closure, there will be a steadily increasing pressure to come up with alternatives in patient care. In discussing the organization of out-patient facilities, we have attempted to describe some of these alternatives.

\section{SUMMARY}

The organization of three main types of outpatient anaesthesia facilities has been discussed. The use of an out-patient facility for minor surgical procedures as a less expensive alternative to in-patient management has been suggested and some of the advantages and disadvantages pointed out.

\section{REFERENCES}

1. Rosoff, C.B. The potential for out-patient surgery. Int. Anesth. Clinies. 14: 2, I-8 (1976).

2. SchmidT, K.F. Evaluation of candidates for outpatient anesthesia and surgery. Int. Anesth. Clinics. 14: 2, 9-13(1976).

3. Tompson, G.E., Remington, J.M., Millman, B.S. \& Bridenbaugh, L.D. Experiences with out-patient anesthesia. Anesth. Analg. 52: 881-887 (1973).

4. REED, W.A. \& ForD, J.L. Development of an independent out-patient surgical centre. Int. Anesth. Clinics, 14: 2, 113-129(1976)

\section{RÉSUMÉ}

Trois types d'installations pour la chirurgie ambulatoire sont discutés: l'unité autonome à l'intérieur de l'hopital, l'unité intégrée et le centre de chirurgie ambulatoire indépendant.

L'utilisation du service de chirurgie ambulatoire a été proposée comme une altemative beaucoup moins côuteuse que l'hospitalisation. Les auteurs en décrivent les avantages et les désavantages. 